\title{
Genomic and immunohistochemical profiles of enteropathy-associated T-cell lymphoma in Japan
}

\author{
Sakura Tomita ${ }^{1}$, Yara Y Kikuti ${ }^{1}$, Joaquim Carreras $^{1}$, Minoru Kojima ${ }^{2}$, Kiyoshi Ando ${ }^{2}$, \\ Hirotaka Takasaki ${ }^{3}$, Rika Sakai ${ }^{3}$, Katsuyoshi Takata ${ }^{4}$, Tadashi Yoshino ${ }^{4}$, Silvia Bea ${ }^{5}$, \\ Elias Campo ${ }^{5}$ and Naoya Nakamura ${ }^{1}$
}

${ }^{1}$ Department of Pathology, Tokai University, School of Medicine, Isehara, Japan; ${ }^{2}$ Department of Hematology, Tokai University, School of Medicine, Isehara, Japan; ${ }^{3}$ Department of Oncology, Kanagawa Cancer Center, Yokohama, Japan; ${ }^{4}$ Department of Pathology, Okayama University Graduate School of Medicine, Dentistry and Pharmaceutical Sciences, Okayama, Japan and ${ }^{5}$ Department of Pathology and Hematopathology Unit, Hospital Clinic Barcelona, Institut d'Investigacions Biomediques August Pi i Sunyer (IDIBAPS), University of Barcelona, Barcelona, Spain

\begin{abstract}
Enteropathy-associated T-cell lymphoma (EATL) is a rare primary T-cell lymphoma of the digestive tract. EATL is classified as either Type I, which is frequently associated with and thought to arise from celiac disease and is primarily observed in Northern Europe, and Type II, which occurs de novo and is distributed all over the world with predominance in Asia. The pathogenesis of EATL in Asia is unknown. We aimed to clarify the histological and genomic profiles of EATL in Japan in a homogeneous series of 20 cases. The cases were characterized by immunohistochemistry, high-resolution oligonucleotide microarray, and fluorescence in situ hybridization (FISH) at five different loci: 1q21.3 (CKS1B), 6q16.3 (HACE1), 7p22.3 (MAFK), 9q33.3 (PPP6C), and 9q34.3 (ASS1, CARD9) using formalin-fixed paraffin-embedded sections. The histological appearance of EATL ranged from medium- to large-sized cells in 13 cases (65\%), small- to medium-sized cells in five cases (25\%), and medium-sized in two cases (10\%). The immunophenotype was CD2+ $(60 \%)$, CD3 $\varepsilon^{+}(100 \%), \mathrm{CD}^{+}(10 \%), \mathrm{CD7}^{+}(95 \%), \mathrm{CD}^{+}(80 \%), \mathrm{CD}^{+} 6^{+}$ $(85 \%), \mathrm{TIA}_{-1}^{+}(100 \%)$, Granzyme $\mathrm{B}^{+}(25 \%)$, T-cell receptor (TCR) $\beta^{+}(10 \%), \mathrm{TCR}^{+}(35 \%), \mathrm{TCR} \gamma \delta^{+}(50 \%)$, and double negative for TCR (six cases, 30\%). All cases were EBER ${ }^{-}$. The genomic profile showed recurrent copy number gains of 1q32.3, 4p15.1, 5q34, 7q34, 8p11.23, 9q22.31, 9q33.2, 9q34.13, and 12p13.31, and losses of 7p14.1. FISH showed 15 patients $(75 \%)$ with a gain of $9 q 34.3$ with good correlation with array comparative genomic hybridization. EATL in Japan is characterized by non-monomorphic cells with a cytotoxic $C D 8^{+}$CD $56^{+}$phenotype similar to EATL Type II. The genomic profile is comparable to EATL of Western countries, with more similarity to Type I (gain of 1q and 5q) rather than Type II (gain of 8q24, including MYC). The 9q34.3 gain was the most frequent change confirmed by FISH irrespective of the cell origin of $\alpha \beta$-T-cells and $\gamma \delta$-T-cells.
\end{abstract}

Modern Pathology (2015) 28, 1286-1296; doi:10.1038/modpathol.2015.85; published online 31 July 2015

Enteropathy-associated T-cell lymphoma (EATL) is a rare type of T-cell lymphoma with extranodal origin, representing $<1 \%$ of malignant lymphomas and $<5 \%$ of digestive tract malignant lymphomas. ${ }^{1,2}$ EATL is frequently associated with intestinal perforations, and diagnosis for EATL is many times delayed because of tumor development in the small

Correspondence: Professor N Nakamura, Department of Pathology, Tokai University School of Medicine, 143 Shimokasuya, Isehara, Kanagawa 259-1193, Japan.

E-mail: naoya@is.icc.u-tokai.ac.jp

Received 18 March 2015; revised 26 May 2015; accepted 27 May 2015; published online 31 July 2015 intestines, which is difficult to explore by routine endoscopic examination and screening. Moreover, effective chemotherapy for EATL has not yet been developed $^{3}$ and prognosis of EATL is very poor. ${ }^{1-3}$

EATL is subclassified into two types according to its clinicopathological characteristics. Type I EATL occurs in association with celiac disease, a gluten intolerance disease. Cases are commonly observed in Northern European countries, particularly in Scandinavia. On the other hand, Type II EATL, which occurs de novo, is found all over the world and with higher frequency in Eastern countries. ${ }^{1-4}$ Celiac disease is quite a rare disease in Asia, and only a few cases of Type I EATL have been reported in 
Japan before the recent introduction of a glutencontaining diet. ${ }^{5,6}$ Prevalence of the HLA-DQ2 and DQ8 haplotypes that are frequently found in celiac disease was reported to be low in the Eastern Hemisphere. $^{7}$ In Asia, almost all EATL cases are classified as Type $\mathrm{II},{ }^{6-9}$ and because of its low incidence, its pathological mechanism and immunohistological findings remain undefined and poorly understood. However, the association of Type II EATL with autoimmune hemolytic anemia is suggestive of a yet unidentified immunological background. ${ }^{10}$

Intraepithelial lymphocytes are thought to be the cell of origin for EATL, and may have a key role in protection from foreign antigens, detachment/elimination of virally infected villous epithelia, and turnover of epithelial cells. ${ }^{11}$ Intraepithelial lymphocytes consist of phenotypically diverse and complex T-cell populations, which differ from the conventional peripheral T-cells. Intraepithelial lymphocytes can express either $\alpha \beta$-T-cell receptor (TCR) or $\gamma \delta$ TCR, and are capable of expressing CD8, granzyme $\mathrm{B}$, and CD103, which confer enterocyte destruction and villous atrophy capabilities. ${ }^{12,13}$

Recently, numerous monoclonal and polyclonal antibodies for formalin-fixed paraffin-embedded tissue sections have been developed. Pan-T-cell antigens such as CD3 and CD5, as well as helper T-cell, cytotoxic T-cell, and $\alpha \beta$ - and $\gamma \delta$-T-cell markers have been made available, aiding in the study of T-cells and their neoplasms; hence, a detailed immunohistochemical analysis of EATL may be performed. Chan et $a .^{8}$ reported that Type II EATL frequently expressed $\gamma \delta$-T-cell markers. Additionally genomic alterations characteristic of EATL in Western countries have been previously reported. By array comparative genomic hybridization, recurrent minimal regions of chromosomal alteration were identified. EATL was initially characterized by $9 \mathrm{q}$ gains (minimal region 9q33-q34). ${ }^{14} \mathrm{~A}$ recent study of western EATL has reported frequent complex gains of 9q31.3-qter (70\%) and loss of 16q12.1 (23\%); and the subtype of EATL Type I was characterized by gains of $1 \mathrm{q}$ and $5 \mathrm{q}$, while Type II EATL was associated with gains in 8q. ${ }^{15}$ In Japan, one study using comparative genomic hybridization analysis identified gains of 8q2 (47\%), Xp (53\%), and Xq $(73 \%)$, but none of the cases had any gains of $1 \mathrm{q} 3$, $5 q 3,7 q 2$, or 9q3, which are typically found in Caucasian EATL patients. ${ }^{6}$ To the best of our knowledge, there have been no reports on the association between $\alpha \beta$ - and $\gamma \delta$-T-cell phenotype markers and genomic alterations.

In the present study, we analyzed the genomic and immunohistochemical profiles of EATL from formalin-fixed paraffin-embedded tissue using an oligonucleotide array-based comparative genomic hybridization technique. We demonstrated that a 9q34 gain was frequently found in Type II EATL derived from both $\alpha \beta$-T-cells and $\gamma \delta$-T-cells.

\section{Materials and methods}

Case Selection, Lymphoma Samples, and Clinical Data

A total of 22 samples from Japanese patients with an initial diagnosis of EATL from 2000 to 2012 were retrieved from the Departments of Pathology of Tokai University, Okayama University, and the Kanagawa Cancer Center. Inclusion criteria were the presence of a lymphoma with EATL morphology and phenotype as established by the 4th edition 2008 WHO classification of lymphomas, which is characterized by a monomorphic diffuse proliferation of lymphoma cells in the lamina propria with infiltration and destruction of different intestinal compartments, and the presence of intraepithelial lymphocytes. Lymphoid cells also must be positive for cytoplasmic CD3 (cCD3; T-cell surface glycoprotein CD3 epsilon chain). Cases of extranodal NK/T-cell lymphoma nasal type were carefully excluded by noting the absence of intraepithelial lymphocytes in cases positive for Epstein-Barr virus Small RNA (EBER) genes by EBER RNA in situ hybridization. Two cases were reclassified, one as extranodal NK/T-cell lymphoma nasal type and another as peripheral T-cell lymphoma not otherwise specified, and therefore excluded. As a result, 20 EATL cases were employed in the present study (Table 1).

The formalin-fixed paraffin-embedded samples were obtained from surgical resection in 15 patients

Table 1 Clinical features of the patients

\begin{tabular}{lllll}
\hline Case & Age & Sex & Location & Treatment \\
\hline 1 & 64 & Female & Small intestine & Operation, EPOCH \\
2 & 62 & Female & Small intestine & $\begin{array}{l}\text { Operation, CHOP } \\
3\end{array}$ \\
66 & Female & Small intestine & Operation \\
4 & 81 & Female & Small intestine & Operation, THP-COP, \\
& & & CDE-11 \\
5 & 76 & Male & Small intestine & Operation, THP-COP \\
6 & 51 & Male & Small intestine & Operation, 50\% CHOP \\
7 & 71 & Male & Small intestine & THP-COP \\
8 & 59 & Male & Small intestine & CHOP \\
9 & 68 & Male & Small intestine & Operation, hyper \\
& & & & CVAD/MA \\
10 & 35 & Male & Small and large & CHOP \\
& & & intestine & \\
11 & 64 & Male & Small intestine & Operation, DeVIC \\
12 & 54 & Male & Ileum & Operation, THP-COP \\
13 & 41 & Male & Small intestine & Operation, DeVIC \\
14 & 61 & Female & Large intestine & Operation, DeVIC \\
15 & 49 & Female & Small intestine & Operation, CHO, GEM \\
16 & 75 & Male & Small intestine & CHO \\
17 & 74 & Female & Small intestine & Operation, CHOP \\
18 & 63 & Male & Large intestine & O \\
19 & 70 & Female & Small intestine & Operation \\
20 & 58 & Male & Jejunum & Operation \\
& & &
\end{tabular}

EPOCH (etoposide, vincristine, doxorubicin, cyclophosphamide, and prednisolone); CHOP (cyclophosphamide, doxorubicin, vincristine, and prednisolone); THP-COP (cyclophosphamide, pirarubicin, vincristine, and prednisolone); CDE-11 (irinotecan, carboplatin, etoposide, and dexamethasone); hyper CVAD/MA (methotrexate, cyclophosphamide, dexamethasone, doxorubicin, vincristine, and cytarabine/methotrexate, cytarabine); DeVIC (carboplatin, ifosfamide, etoposide, and dexamethasone); CHO (cyclophosphamide, doxorubicin, and vincristine); GEM (gemcitabine). 
and tumor biopsy in five patients. Clinical findings were collected from written description. Of note, none of the EATL cases had a history of celiac disease. This study was approved by the institutional review board of the participating institutions where required (12R-084), was conducted in accordance with the Helsinki Declaration of 1975 as revised in 2008 and with accordance with the ethical standards on human experimentation. There is compliance with BRISQ, MIAME and REMARK guidelines.

\section{Histological Evaluation}

Lymphoma cells were categorized by size (small, medium, or large) and nuclear configuration (round or irregular), and investigated for the presence of intraepithelial lymphocytes by hematoxylin-eosin (HE) stain.

\section{In Situ Hybridization of EBV-Encoded RNA (EBER In Situ Hybridization) and Immunohistochemistry}

EBER in situ hybridization was performed using Bond ready-to-use in situ hybridization EBER fluorescein-conjugated oligonucleotide probe (PB0589, Leica Biosystems, Novocastra (NV), Newcastle upon Tyne, UK) and the purified IgG fraction of a mouse monoclonal anti-fluorescein antibody (NV, AR0833). For immunohistochemistry, mouse monoclonal antibodies against CD2 (NV, clone LFA), CD3\& (NV, clone LN10), CD4 (NV, clone 4B12), CD5 (NV, clone 4C7), CD7 (NV, clone LP15), CD8 (NV, clone 4B11), CD10 (NV, clone 56C6), CD20 (Nichirei, clone L26), CD56 (NV, clone CD564), TIA-1 (Beckman Coulter, clone 2G9A10F5), Granzyme B (NV, clone 11F1), TNFRSF (Abcam, ab47677, rabbit polyclonal) TCR $\beta$ (Human TCR beta chain constant region, Santa Cruz, G-11), TCR $\gamma$ (Human TCR gamma chain constant region, Thermo Scientific, TCR C gamma M1 antibody clone $\gamma 3.20$ ), and TCR $\gamma \delta$ (Human TCR Pan TCR gamma delta, Thermo Scientific, TCR gamma+delta antibody clone 5A6. E9) were purchased as primary antibodies. BTLA was provided from Spanish National Cancer Research Center. Detection of EBER in situ hybridization and immunohistochemistry signals was performed using the Leica BOND-MAX fully automatic immunohistochemistry system with the BOND Polymer Refine detection kit (DS9800) according to the manufacturer's instructions. BOND Epitope Retrieval Solution 2 (AR9640) was used for $20 \mathrm{~min}$ for CD2, CD3, CD4, CD5, CD7, CD8, CD20, CD56, TIA-1, Granzyme B, TNFRSF, BTLA and TCR $\beta$. Epitope retrieval of TCR $\gamma$ was performed with a pressure cooker (Asahi e-range pressure cooker RC-11, Japan) inside a microwave (Panasonic NE-EA212 high power $750 \mathrm{~W}$ ) in EDTA (pH9.0) antigen retrieval solution for $4 \mathrm{~min}$, and for TCR $\gamma \delta$ by microwaving to boiling point in EDTA (pH9.0) for $20 \mathrm{~min}$; these were then stained by Leica BOND-MAX system. The cutoff value for sample positivity was set at $30 \%$ of positive lymphoma cells.

\section{DNA Extraction and Array Comparative Genomic Hybridization}

Slides containing at least 70\% lymphoma cells based on histology and immunohistochemistry were selected for crude micro-dissection and DNA extraction. DNA was extracted from formalin-fixed paraffin-embedded slides of surgically resected tissue using a silica-membrane-based DNA purification method (QIAamp DNA Micro Kit, Cat. no. 56304, QIAGEN K.K., Japan). All extracted DNA samples were assessed for quality by PCR amplification as previously described by BIOMED-2 guidelines, ${ }^{16}$ and eight cases with optimal genomic fragments larger than $200 \mathrm{bp}$ were subjected to array comparative genomic hybridization. Array comparative genomic hybridization was performed hybridizing $1.5 \mu \mathrm{g}$ of test DNA of a sex-matched reference on a SurePrint G3 Human array comparative genomic hybridization. Array comparative genomic hybridization microarray 1M (Agilent Technologies, USA), following the protocol 'Oligonucleotide Array-Based for Genomic DNA Analysis’ (Agilent ULS labeling for blood, cells, tissues or formalin-fixed paraffinembedded tissues). Array comparative genomic hybridization was outsourced to Quantitative Genomic Medicine Laboratories (qGenomics, Spain). As previously described by Salaverria et al. ${ }^{17}$ 'Protocol Version 3.1' was followed with slight modifications. Briefly, after digestion, the DNA was fragmented $\left(99^{\circ} \mathrm{C}\right.$ for $\left.40 \mathrm{~min}\right)$ and labeled. After hybridization, the slides were washed and fluorescence was assessed using a DNA microarray scanner (G2565CA, Agilent Technologies). Raw data were generated from scanned images using the Agilent Feature Extraction Software (v10.7). Log2 ratios of background-corrected tumor over normal DNA values were calculated. Normalization was carried out on Agilent's comparative genomic hybridization analytics, integrated on the Genomic Workbench suite (v5.0). Detection of copy number alterations was performed using the Aberration Detection Method-2 (ADM-2) algorithm, implemented within Agilent's genomics suite Genomic Workbench v5.0 and Nexus Copy Number software v6.0 Discovery Edition (BioDiscovery, USA). The results were concordant with both algorithms. All alterations were confirmed by visual inspection by two different observers. Regions of alterations (ROAs) were identified as previously described by Deleeuw et al. ${ }^{15}$ based on the frequency and exclusivity of genes or losses and the minimal common regions identified. The Waves array comparative genomic hybridization Correction Algorithm (WACA), based on GC content and fragment size adjustment was applied in several cases. ${ }^{18}$ WACA efficiently removes the wave artifact, thereby greatly improving the accuracy of array 
comparative genomic hybridization data analysis. Copy number variations/polymorphisms were identified and excluded from further analyses. Regions showing aberrant copy number changes were mapped according to the human reference sequence (NCBI36/hg18).

\section{FISH Analyses}

Based on the results obtained by array comparative genomic hybridization, the minimal common regions for copy number gains or losses were examined, including a search of potential relevant biomarkers. The resulting loci and targets were tested by fluorescence in situ hybridization (FISH), using either commercial or in-house FISH probes with the corresponding chromosome enumeration probe (CEP). The copy number change for 9q34 was validated with the commercial LSI 9q34 Spectrum Aqua Probe (Vysis) and CEP9 Spectrum Orange Probe (Vysis). In-house FISH probes targeted 1q21.3 (RP11-307C12, CKS1B as the target), 6q16.3 (RP11460L11 - RP11-809N15, HACE1), 7p22.3 (RP1116P10, MAFK), 9q33.3 (RP11-258M22, PPP6C), and 9q34.3 (RP11-413M3, CARD9). Generation of FISH probes and the FISH technique were previously described. ${ }^{19-21}$ BAC clones were labeled with Spectrum Green by nick translation (Abbott Laboratories, UK). Commercial probes were used with the Vysis paraffin pretreatment kit II (7J02-02, Vysis). Experiments were performed blinded to the array comparative genomic hybridization data. Image acquisition and processing was performed using a fluorescence microscope (Olympus BX51, Olympus K.K., Japan), Olympus DP70 digital camera system, and Olympus PD Controller v.1.1.1.65 and PD Manager v.1.1.1.71.

FISH signals were counted in at least 100 cells for each case and results were expressed by mean and standard deviation. Each of the FISH probes were investigated in ten reactive lymphoid tissues (tonsil and reactive lymph node) and the positivity threshold was set at mean \pm 2 s.d. ( $2 x S T D)$.

\section{Results}

\section{Histology, EBER In Situ Hybridization and Immunohistochemistry}

Histological findings of EATL by HE staining in the 20 cases are shown in Table 2 and Figures 1 and 2. A diffuse proliferation of small- to medium-sized cells were observed in five EATL cases (25\%), mediumsized cells in two cases (10\%), and medium- to largesized cells in 13 cases (65\%). All EATL cases had increased numbers of intraepithelial lymphocytes. Nevertheless, histologic evidence of celiac disease in the adjacent mucosa of the lymphoma such as villous blunting/atrophy and crypt hyperplasia were not found. In seven cases (35\%) the intraepithelial lymphocytes were seen not only in the vicinity of the

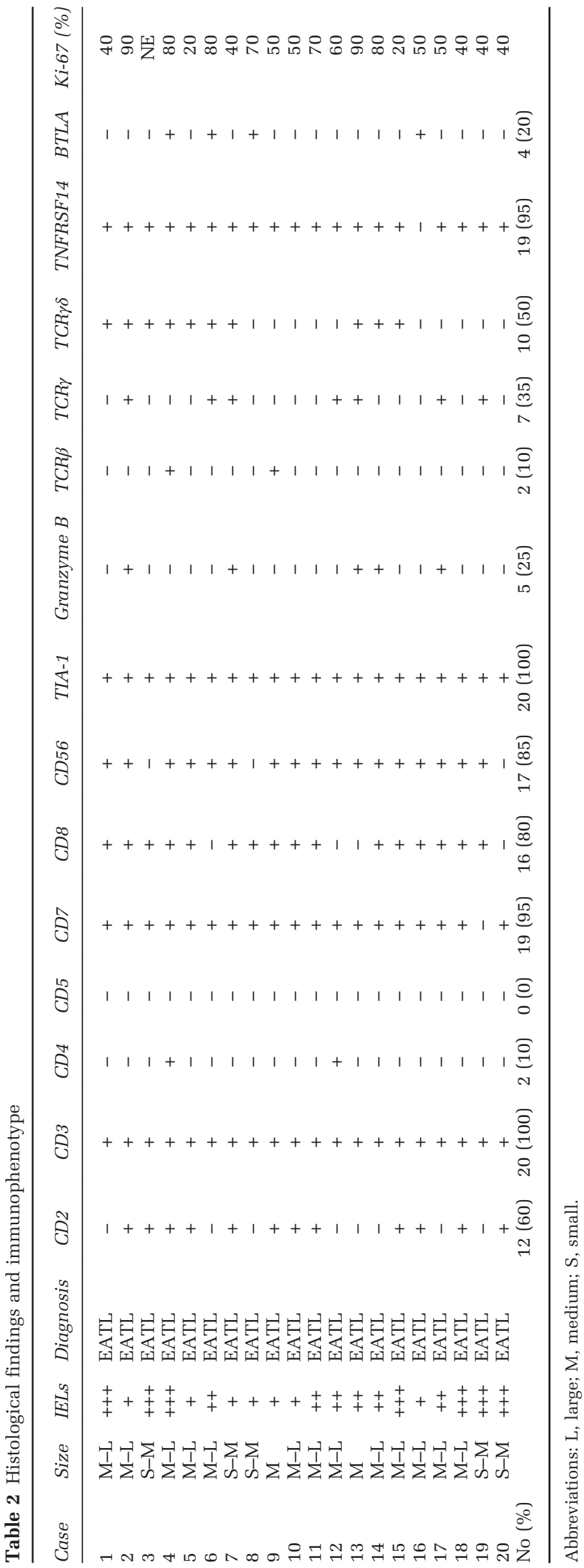




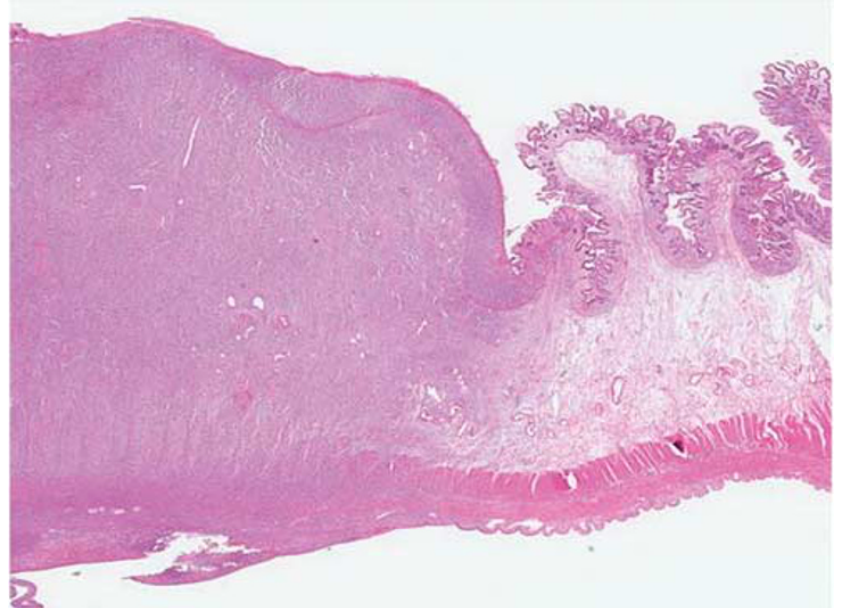

Figure 1 Low-magnification view of enteropathy-associated T-cell lymphoma and the adjacent wall of the intestinal tract. The lymphoma cells are proliferating in all layers. Villous blunting in villi is not evident. lymphoma but also at a distance from the main lesion in a greater or lesser degree. Necrosis was found in the tumor in three cases $(15 \%)$. Reactive small T-cells showing a CD $3 \varepsilon^{+} / \mathrm{CD}^{+}$phenotype admixing with the neoplastic cells were observed in all cases but eosinophils, macrophages, and plasma cells were scarce.

Results of EBER in situ hybridization and immunohistochemistry are shown in Table 2 and Figure 2. Expression of markers (positive cases/examined cases; percentage) in lymphoma cells were as follows: $\operatorname{EBER}(0 / 20,0 \%)$; CD2 (12/20, 60\%); CD3 $\varepsilon$ (20/20, $100 \%)$; CD4 (2/20, $10 \%)$; CD5 $(0 / 20,0 \%)$; CD7 (19/20, 95\%); CD8 (16/20, 80\%); CD56 (17/20, $85 \%)$; TIA-1 (20/20, $100 \%)$; Granzyme B $(5 / 20$, $25 \%) ; \operatorname{TCR} \beta(2 / 20,10 \%) ; \operatorname{TCR} \gamma(7 / 20,35 \%) ; \operatorname{TCR} \gamma \delta$ (10/20, 50\%); TNFRSF14 (19/20, 95\%); and BTLA $(4 / 20 ; 20 \%)$. The Ki-67 index ranged from 20 to $90 \%$ with a mean \pm STD of $50 \% \pm 21.7$.
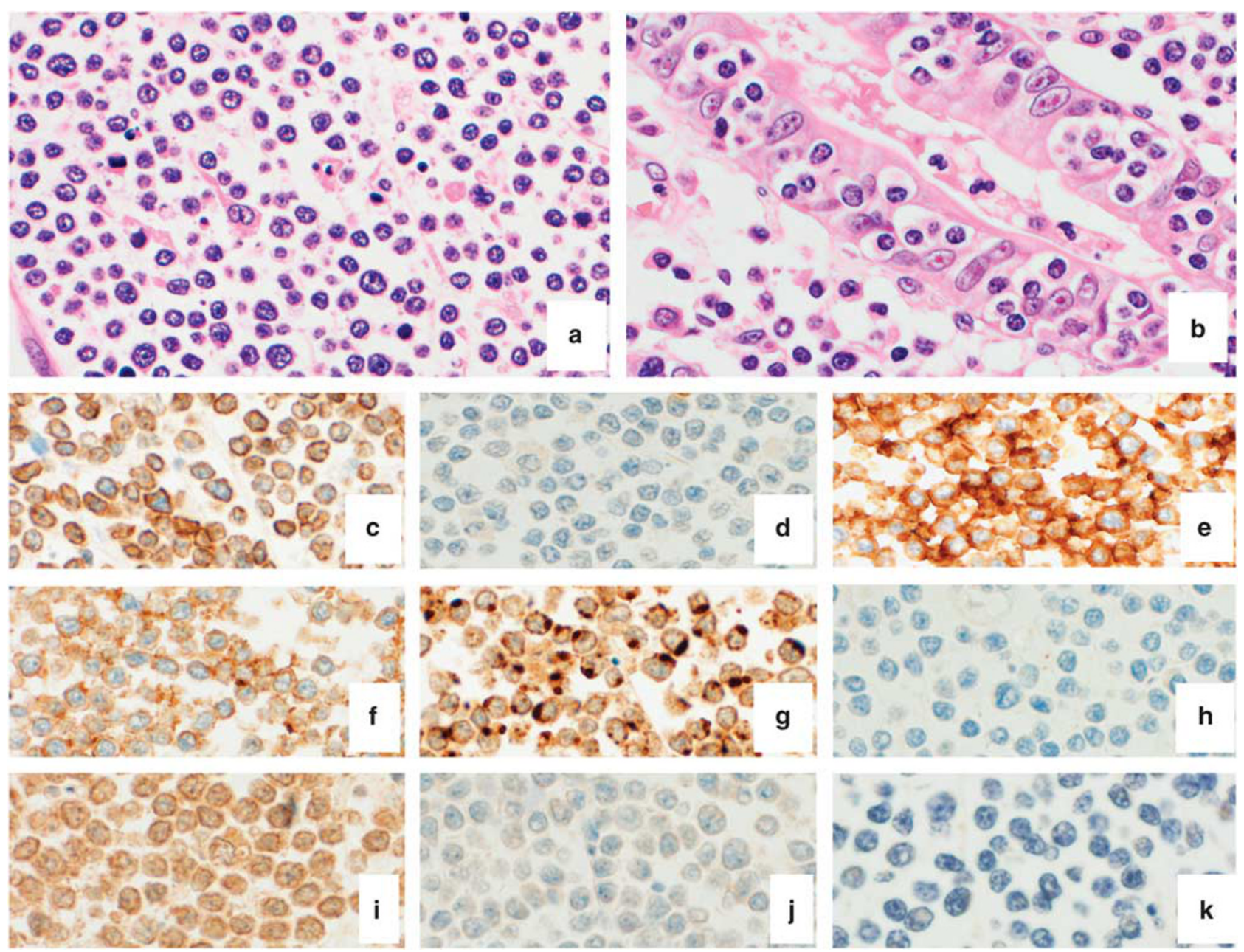

Figure 2 Phenotypic characteristics of enteropathy-associated T-cell lymphoma in Japan. Enteropathy-associated T-cell lymphoma in Japan is comprised of a heterogeneous lymphoid population from medium- to large-sized cells (a) with increased numbers of IELs (b), and with a characteristic phenotype similar to a cytotoxic CD8 ${ }^{+} \mathrm{CD}^{+} 6^{+}$lymphocyte. This figure shows a characteristic case where the lymphoma cells are CD3 ${ }^{+}(\mathbf{c}), \mathrm{CD}^{-}(\mathbf{d}), \mathrm{CD}^{+}(\mathbf{e}), \mathrm{CD}^{+} 6^{+}(\mathbf{f}), \mathrm{TIA}_{-}{ }^{+}(\mathbf{g}), \mathrm{TCR} \beta^{-}(\mathbf{h}), \mathrm{TCR} \gamma \delta^{+}(\mathbf{i}), \mathrm{TCR} \gamma^{-}(\mathbf{j})$ and Epstein-Barr virus small RNA in situ hybridization-negative (k). 

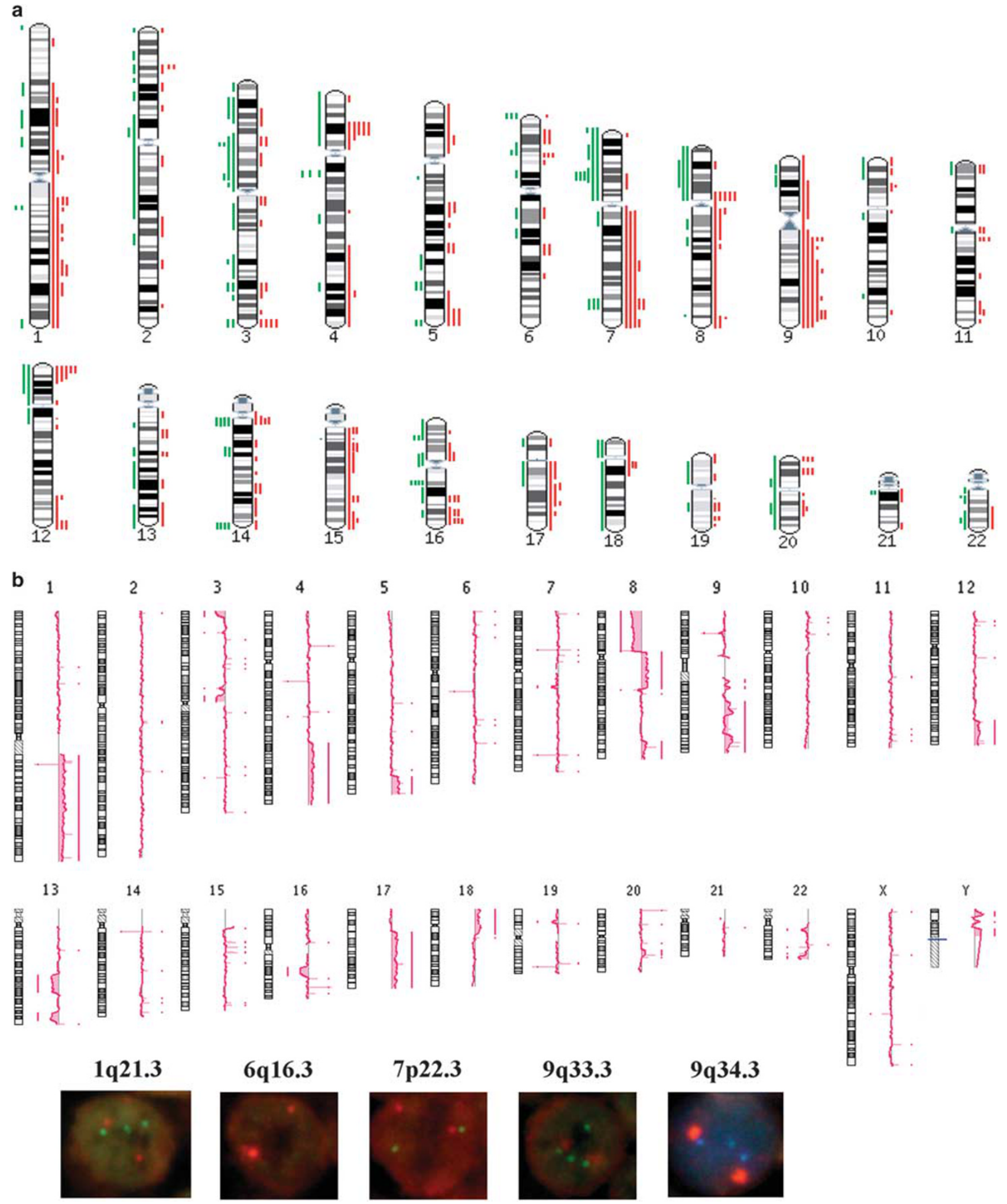

Figure 3 (a) Summary view of the copy number alterations across the genome. The karyoview of enteropathy-associated T-cell lymphoma in Japan showed multiple regions of gains and losses such as gain of 4p15.1 (5/8, 63\%), 7q34 (5/8, 63\%), 8p11.23 (5/8, 63\%), 9q22.31 (5/8, $63 \%)$, 9q33.2 (5/8,63\%), 9q34.13 (6/8, 75\%) and losses of 7p14.1 (6/8,75\%). (b) Genomic profile of enteropathy-associated T-cell lymphoma case 11. This figure depicts the copy number changes for the enteropathy-associated T-cell lymphoma case 11. Deviations of the log2 ratios to the right represent gains and to the left losses; above them a line or dot is plotted depending on the copy number length. Below the karyoview the results for case 11 of fluorescence in situ hybridization targeting band 1q21.3, 6q16.3, 7p22.3, and 9q34.3 are presented. CEP1, 6, 7, and 9 (orange); 1q, 6q, and 7 (green); and 9q34 (aqua). 
Table 3 Genomic copy number changes in each case by human genome CGH microarray

Chromosomal changes

\begin{tabular}{|c|c|c|}
\hline Case & Copy number gains & Copy number losses \\
\hline 1 & $9 q 33.2,9 q 34.13$ & - \\
\hline 4 & 5p15.33-p12, 7q11.21-q36.3, 9q22.1-q34.3 & $\begin{array}{c}\text { 3p21.31-p12.1, 7p22.3-p11.1, 10p15.3-p14, } \\
\text { 12p13.33-p12.1, 13q32.3-q34, 18p11.32-p11.21 }\end{array}$ \\
\hline 11 & $\begin{array}{c}\text { 1q21.1-q44, 4q28.2-q35.2, 5q34-q35.3, 8p11.21- } \\
\text { q11.1, 8q11.1-q21.11, 8q24.21-q24.3, 9q21.33-q34.3, } \\
\text { 12q24.11-q24.33, 17q11.1-q25.3, 17q22, 18p11.32- } \\
\text { q11.1 }\end{array}$ & $\begin{array}{l}\text { 3p12.3, 3q26.1, 7q11.23, 8p23.3-p11.21, 8p11.23- } \\
\text { p11.22, 13q21.32-q31.1, 13q33.1 - q34, -16q21 - q22.1 }\end{array}$ \\
\hline 14 & $1 \mathrm{q} 21.3,9 \mathrm{q} 34.13,12 \mathrm{p} 13.31-\mathrm{p} 13.2$ & $\begin{array}{c}\text { 3p24.3-p23, 3p21.31-p12.3, 3q12.3-q13.2, 3q24- } \\
\text { q25.2, 16p13.3-p13.12 }\end{array}$ \\
\hline 15 & 9p24.3-p11.1, 9q13-q34.3, 18q11.1-11.2 & 18p11.32-p11.21, 18q11.2-q23 \\
\hline 17 & 4p14-p11, 7q11.22-q36.3, 15q11.2-q26.3 & $\begin{array}{c}\text { 3p21.31, 4p16.3-p14, 8p23.3-p11.1, 12p13.2-p11.1, } \\
\text { 12q11-q13.11, 20p13-q11.1 }\end{array}$ \\
\hline 19 & $\begin{array}{c}\text { 1p32.2-p11.2, 1q21.1-q44, 7q11.21-q36.3, 8q11.22- } \\
\text { q24.3, 9q13-q34.13 }\end{array}$ & $\begin{array}{l}\text { 2p13.2-p11.2, 2p11.2-q11.1, 2q11.1-q23.3, 7p22.3- } \\
\text { p11.1, 8p22-p12 }\end{array}$ \\
\hline 20 & $7 q 11.21-\mathrm{g} 36.1$ & 7p22.3-p11.1, 16q11.2-q24.3 \\
\hline
\end{tabular}

Regions of interest for FISH validation

\begin{tabular}{|c|c|c|c|c|c|}
\hline Locus & Start bp & End $b p$ & $\begin{array}{l}\text { No of } \\
\text { genes }\end{array}$ & Target genes & Filtered by $G O$ accession \\
\hline $1 \mathrm{q}$ & 150853058 & 201504239 & 34 & $\begin{array}{l}\text { TIPRL, CKS1B, RGS2, CDC73, } \\
\text { PRCC }\end{array}$ & $\begin{array}{l}\text { Cell cycle (GO:0007049); } \\
\text { oncogenesis (GO:0007048); } \\
\text { lymphoma }\end{array}$ \\
\hline $6 q$ & 95601978 & 95641552 & 1 & MANEA & $\begin{array}{l}\text { Post-translational protein } \\
\text { modification (GO:0043687) }\end{array}$ \\
\hline $7 p$ & 293816 & 20689516 & 37 & $\begin{array}{l}\text { DGKB, GNA12, ETV1, RPA3, } \\
\text { GPER1, RAC1, MAFK, ADAP1, } \\
\text { RBAK, C1GALT1, PDGFA, } \\
\text { HDAC9,CARD11 }\end{array}$ & $\begin{array}{l}\text { DNA-binding transcription } \\
\text { factor, nucleoplasm (GO } \\
\text { evidence code TAS) }\end{array}$ \\
\hline $9 q$ & 133531096 & 139816430 & 7 & $\begin{array}{l}\text { FCN1, FCN2, C8G, TUBB } 4 B, \\
\text { TRAF2, VAV2, CARD9 }\end{array}$ & $\begin{array}{l}\text { Innate immune response } \\
\text { (GO:0045087) }\end{array}$ \\
\hline
\end{tabular}

The genes marked in bold are the target genes selected for FISH analysis.

\section{Genomic Profile}

Samples of good-quality DNA control gene PCR band $>200$ bp were obtained from eight formalin-fixed paraffin-embedded specimens. All cases except one showed multiple genetic alterations throughout the genome (Figure 3a). Table 3 shows the detailed genomic profile of each case. Recurrent gains were found at $1 \mathrm{q} 32.3$ (4/8, 50\%), 4p15.1 (5/8, 63\%), 5q34 (3/8, 38\%), 7q34 (5/8, 63\%), 8p11.23 (5/8,63\%), 8q24 (3/8, 38\%), 9q22.31 (5/8, 63\%), 9q33.2 (5/8, 63\%), and $9 q 34.13(6 / 8,75 \%)$, and losses at 7 p14.1 $(6 / 8$, $75 \%), 8 p 23.3-p 11.21(3 / 8,38 \%)$ and $16 q(4 / 8,50 \%)$.

Region of alteration 1q21 ranged from 150853058 to 201504239, containing 34 genes, the most relevant of which were TIPRL, CKS1B, RGS2, CDC73, and PRCC (region filtered by cell cycle and oncogenesis). Region 6q16 ranged from 95601978 to 95641552 containing only one gene: MANEA (post-translational protein modification). ROA $7 \mathrm{p} 22$ ranged from 293816 to 20689516, containing 37 genes and the most relevant of which were DGKB, GNA12, ETV1, RPA3, GPER1, RAC1, MAFK, ADAP1, RBAK, C1GALT1, PDGFA, HDAC9, and CARD11 (DNA-binding transcription factor, nucleoplasm). ROA 9q34 ranged from
133531096 to 139816430 , containing seven genes: FCN1; FCN2; C8G; TUBB4B; TRAF2; VAV2; and CARD9 (innate immune response).

\section{Fluorescence In Situ Hybridization}

A target gene with biological sense was selected from each of the ROAs for the FISH analysis (Figure 4). Cutoff values for each FISH probe for copy number gains and losses are shown in Table 4. Cutoff values for gains were $4 \%, 19 \%, 13 \%, 20 \%$, and $17 \%$ for the 1q21, 6q16, 7p22, 9q33, and 9q34 bands, respectively. For losses, the cutoff values were $73 \%, 62 \%, 60 \%$, $70 \%$, and ND, respectively. In the eight cases with array comparative genomic hybridization results, good correlation between FISH and array comparative genomic hybridization was observed $(64 \%$ of agreement). Of note, the agreement reached a $82 \%$ when a minimum of $30 \%$ of EATL cells with FISH alterations were set up as threshold for array comparative genomic hybridization technique sensitivity; reaching perfect $100 \%$ correlation for $9 \mathrm{q} 34$ locus.

The FISH analysis was expanded to the 12 additional cases with no array comparative genomic 
hybridization results available. Overall, FISH showed $15 / 20$ patients $(75 \%)$ with a gain of $9 \mathrm{q} 34$ (ASS1), with good correlation between array comparative genomic hybridization results (88\%). Gains of 1q21.3 (CKS1B), 6q16.3 (HACE1), 7p22.3 (MAFK), 9q33.3 (PPP6C), and 9q34.4 (CARD9) were observed in $12 / 18(67 \%), 6 / 16(38 \%), 1 / 13(8 \%), 6 / 15(40 \%)$, and $12 / 17(71 \%)$ cases, respectively. Losses of $6 q 16$ and 7 p22 were observed in $1 / 16(6 \%)$ and $5 / 13$ $(39 \%)$ cases (positive/ examined cases). No cases showed any loss of 1q21 or 9q33.

No differences were observed between the different EATL TCR phenotypes (TCR $\beta, \gamma \delta$ and -/-) regarding the genomic profiles of array comparative genomic hybridization and FISH.

\section{Discussion}

In the present study, we investigated the genomic and immunohistochemical profiles of EATL cases in Japan using formalin-fixed paraffin-embedded samples. EATL is an uncommon lymphoma of intestinal intraepithelial lymphocytes associated with celiac disease, with a higher frequency of incidence in Northern Europe. Data of EATL occurrence in Asian countries as well as its clinicopathological characteristics are limited. Types I and II EATLs differ in terms of histological appearance, whereas in Western countries EATL Type II is characterized by small- to medium-sized tumor cells, ${ }^{1,2}$ the majority of our Japanese cases showed medium to large tumor cell proliferation $(13 / 20,65 \%)$. Chan et al. ${ }^{8}$ described that there was some degree of nuclear size variation in tumor cells of Chinese EATL. Our cases showed similarity to those cases. Therefore, size variation in tumor cells is characteristics of Asian cases and that may be one of differences from Western cases. Because no history of celiac disease was present in our series, we conclude that there may be some different immunological background characteristics in Japanese cases of EATL.

The phenotypic profile of Japanese EATL corresponded to cytotoxic CD8-positive and CD56-positive intraepithelial lymphocytes. Immunohistochemistry in our series revealed that the tumor cells frequently expressed CD8 (16/20, 80\%) and CD56 (17/20, 85\%). These results are consistent with the immunophenotype of Type II EATL as previously described. ${ }^{1-6}$ In the present study, a high proportion of cases expressed $\gamma \delta$-TCR $(10 / 20,50 \%)$, and six cases were negative for both $\alpha \beta$ and $\gamma \delta$-TCR, a finding that differs from the description in the WHO classification, which states that EATL Type II cases express $\alpha \beta$ TCR. Tan et al. ${ }^{7}$ reported predominant expression of $\alpha \beta$-TCR over $\gamma \delta$-TCR, and Chan et al. ${ }^{8}$ reported that $78 \%$ of Type II EATL cases expressed $\gamma \delta$-TCR. Our results confirm that the expression of $\gamma \delta$-TCR is frequently associated to the EATL Type II in Asia. Three cases $(12,17$, and 19) expressed $\gamma$-TCR but were negative for $\gamma \delta$-TCR. Estimation of the $\gamma \delta$-TCR antibody is controversial. A study using the same antibody (TCR gamma+delta antibody clone 5A6.E9) can successfully recognize $\gamma \delta$-T-cells with membranous staining in formalin-fixed paraffin-embedded tissue, ${ }^{22}$ but there was another one reporting that the antibody was not so robust. ${ }^{23}$ Although membranous positive-staining of $\gamma \delta$-TCR is acceptable as positive, we need further study for $\gamma \delta$-TCR.

The genomic profile of Japanese EATL was characterized by multiple regions of copy number gains and losses as shown in the karyoview (Figure 3). From the most common and/or characteristic abnormal loci, the ROAs and minimal common regions and gene candidates were found and selected genes validated by FISH. It has been reported that EATL is characterized by recurrent gains of $1 \mathrm{q}, 5 \mathrm{q}$, $7 \mathrm{q}$, and recurrent losses of $8 \mathrm{p}, 9 \mathrm{p}$, and $13 \mathrm{q}$, with gains of 9q33-q34 being the most frequent alteration (60\% of frequency). ${ }^{15}$ In line with those previous findings, the present series of EATL was characterized by multiple common and distinct imbalances. In contrast to other types of tumors, the EATL profile did not have a single or unique alteration, but rather have multiple regions, an observation that supports the view that EATL is a multifactorial and polygenic (complex) disorder. It was reported that Type I EATL frequently shows chromosomal gains of 5q34-q35.2 and 1q32.2-q41, while Type II is more often characterized by amplification of 8q24. Deletion of 16q12.1 and amplification of 9q31.3-qter chromosomal regions is frequently observed in both Type I and II EATLs. We demonstrated a large number of genetic abnormalities in our Type II EATLs: gains of 1q, 5q, $7 q$, and $9 q$, and losses of $8 p, 9 p$, and $13 q$, with the most common gain of 9q33-q34 (58\%). The general profile is in concordance with previously reported data from BAC-arrays of Deleeuw et al. ${ }^{15}$ Our highresolution array comparative genomic hybridization and expanded FISH analysis in a series of EATL Type II in Japan has identified a genomic profile similar to EATL of Western countries with characteristics of both Types I and II. Despite that our cases are phenotypically more similar to EATL Type II the histology of the tumor cells is more heterogeneous and range from small to large; and the genomic profile lacks the EATL Type II characteristic genomic copy number gain of $M Y C$ oncogene locus at $8 q 24$ but has the $1 \mathrm{q} 32$ and $5 \mathrm{q} 34$ gains previously described as characteristic of EATL Type I. The results of this study, therefore, raise the question of whether in Asian countries the distinction between EATL Type I and II may not be as clear as previously thought. Of note, the gain at 9q34 loci was the most frequent copy number change confirmed by FISH (ASS1) in $75 \%$ of the cases.

Takeshita et al. ${ }^{6}$ previously reported that only $7 \%$ of cases had an amplification of the 9q band in EATL cases in Japan by metaphase comparative genomic hybridization. Our series has refined and expand these findings observing a gain of $9 \mathrm{q} 34$ in $75 \%$ of 

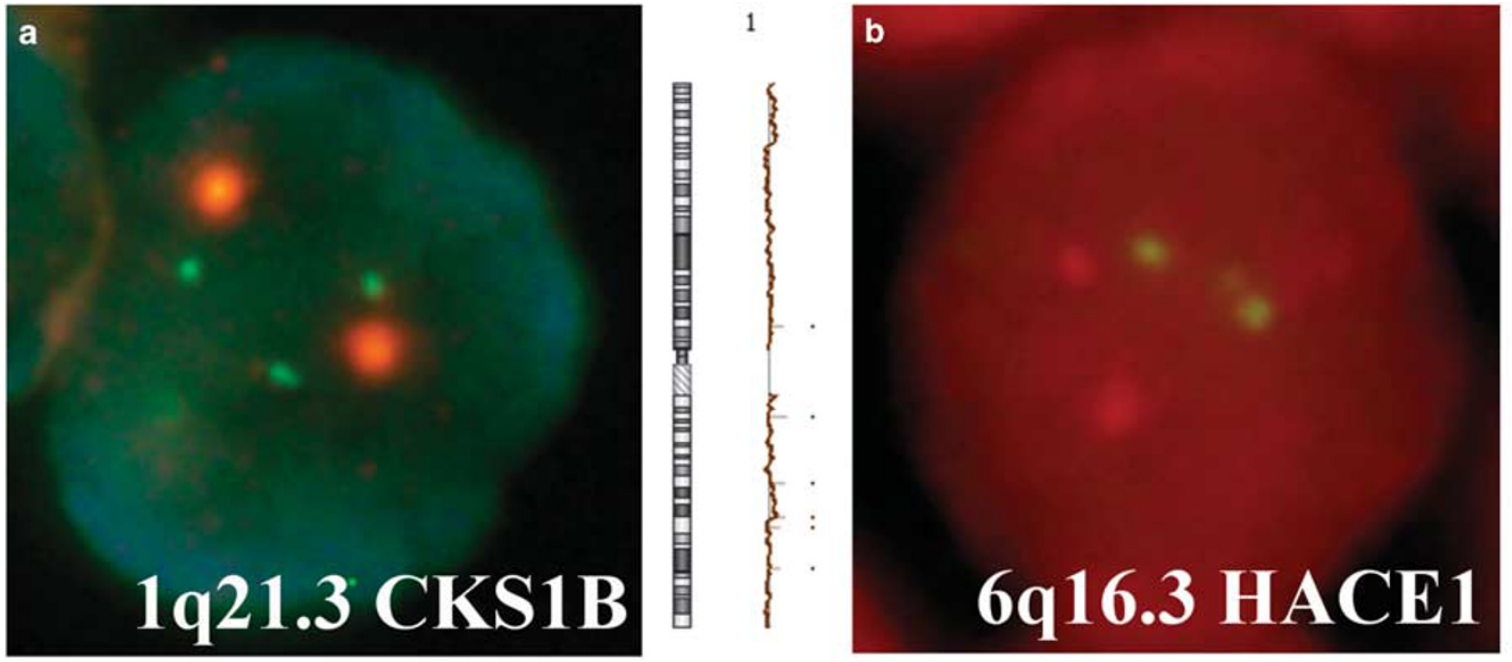

$\theta$
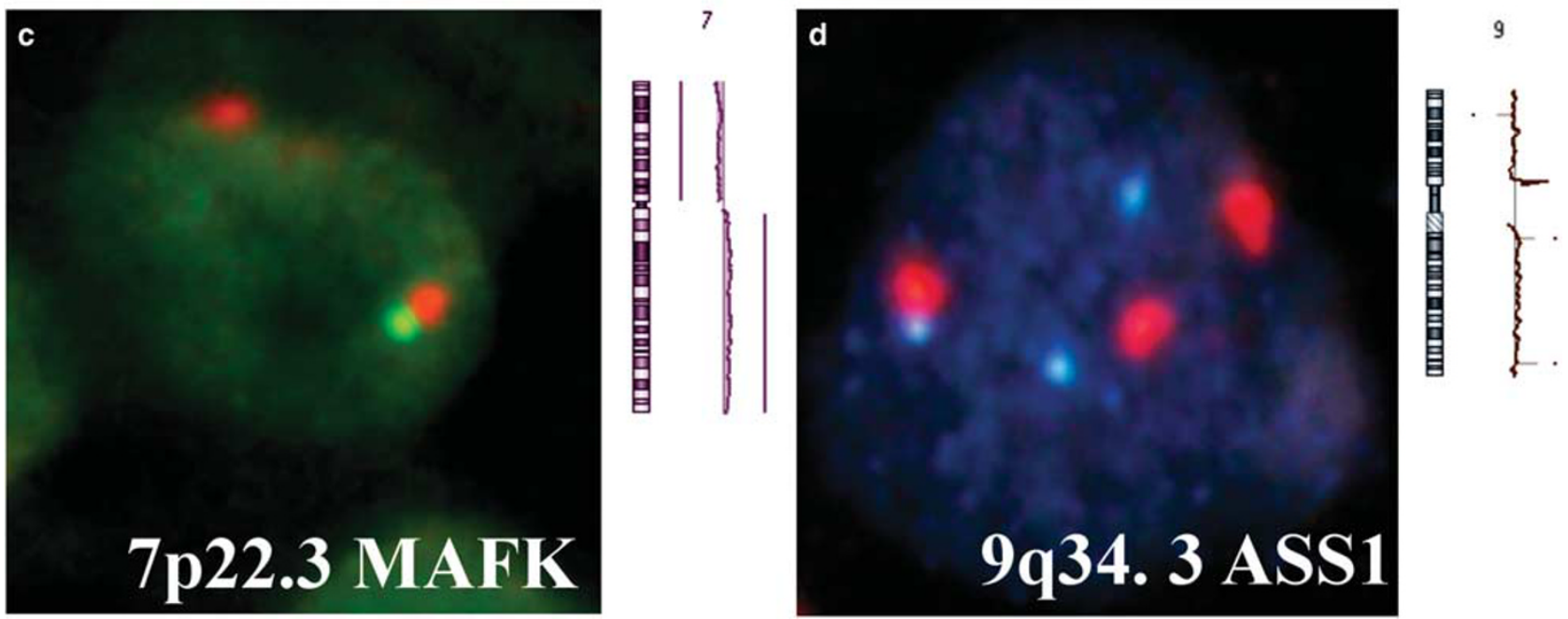

Figure 4 Correlation between microarray and fluorescence in situ hybridization findings. This figure shows the correlation between microarray and fluorescence in situ hybridization at four different locations. In-house probes (1q21.3, CSK1B; 6q16.3, HACE1; and 7p22.3, $M A F K$; green signals) and commercial probe (9q34.3, ASS1, aqua signals) with the corresponding chromosome enumeration probe (orange). (a) Chromosomal gain at 1q21 (three green and two orange signals); (b) no change at 6q16 (two green and two orange signals); (c) loss at 7p22 (one green and two orange signals); and (d) gain of 9q34 (three aqua and three orange signals). Of note, good correlation with the array comparative genomic hybridization results was observed for those cases (the figure depicts the waves array comparative genomic hybridization correction algorithm plots)

cases and confirmed in $75 \%(A S S 1)$ and $71 \%$ $(C A R D 9)$ of cases by FISH. Nevertheless, there was no deletion of 16q12.1. Gain of the 9q33 band was observed in $50 \%(4 / 8)$ of cases by array comparative genomic hybridization and in $43 \%(6 / 14)$ by FISH. A good correlation was found at the 9q34 band between array comparative genomic hybridization and FISH. Therefore, we propose that gain of 9q34 is frequent in Japanese EATL cases, similar to the European series. ${ }^{14,15}$ Among other important gene targets, the target gene CARD9 was selected for FISH validation in the 9q34 region. CARD9 is an oncogene regulator of the ITAM-mediated signaling pathway, forming a complex with BCL10-MALT1, and is a regulatory mechanism for NFKB and MAPK activation through innate and adaptive immunereceptors. ${ }^{14}$ Importantly, CARD9 is abundantly expressed in MALT lymphoma and DLBCL. ${ }^{24-26}$ At 9q34 band we also investigated by FISH by commercial probe the locus containing the tumor suppressor gene of ASS1.

Gain at the $1 \mathrm{q}$ region has been described in both refractory celiac disease IEL cell lines and EATL by metaphase $^{27}$ and array comparative genomic hybridization (Carreras and co-workers, unpublished observations). By array comparative genomic hybridization, our series showed 1q21 gain in 38\% (3/8) of cases with $C K S 1 B$ as the target gene, a cell cycle regulator. Subsequent FISH screening of the entire EATL series confirmed gain in $67 \%(12 / 18)$ of cases. $C K S 1 B$ is known to have an oncogenic role in the pathogenesis of hematological malignancies such as mantle cell lymphoma and follicular lymphoma. ${ }^{28,29}$ Therefore, CKS1B may similarly be associated with EATL lymphomagenesis.

At 6q16, the region of interest contained only one gene: MANEA. However, we selected HACE1 as the 
Table 4 Correlation between microarray and FISH findings

\begin{tabular}{|c|c|c|c|c|c|c|c|c|c|c|c|}
\hline \multirow{4}{*}{$\begin{array}{l}\text { Loci } \\
\text { Gene } \\
\text { Case }\end{array}$} & \multicolumn{11}{|c|}{ Chromosomal loci } \\
\hline & \multicolumn{2}{|c|}{$1 q 21.3$} & \multicolumn{2}{|c|}{$6 q 16.3$} & \multicolumn{2}{|c|}{$7 p 22.3$} & \multicolumn{2}{|c|}{$9 q 33.3$} & \multicolumn{3}{|c|}{$9 q 34.3$} \\
\hline & \multicolumn{2}{|c|}{$C K S 1 B$} & \multicolumn{2}{|c|}{ HACE1 } & \multicolumn{2}{|c|}{$M A F K$} & \multicolumn{2}{|c|}{ PPP6C } & \multirow{2}{*}{$\begin{array}{c}\text { ASS1 } \\
\text { FISH }\end{array}$} & \multicolumn{2}{|c|}{ CARD9 } \\
\hline & FISH & $C G H$ & FISH & CGH & FISH & CGH & FISH & $C G H$ & & FISH & $C G H$ \\
\hline 1 & $\mathrm{~N}$ & $\mathrm{~L}$ & G (26\%) & $\mathrm{N}$ & $\mathrm{N}$ & $\mathrm{N}$ & G (23\%) & $\mathrm{N}$ & G $(25 \%)$ & $\mathrm{N}(15 \%)$ & $\mathrm{G}$ \\
\hline 2 & G (8\%) & - & G (21\%) & - & L (71\%) & - & $\mathrm{N}$ & - & G $(23 \%)$ & $\mathrm{N}(13 \%)$ & - \\
\hline 3 & - & - & - & - & - & - & - & - & $\mathrm{G}(25 \%)$ & - & - \\
\hline 4 & G (8\%) & $\mathrm{N}$ & $\mathrm{N}$ & $\mathrm{N}$ & L (71\%) & $\mathrm{L}$ & G (45\%) & G & G $(33 \%)$ & G (31\%) & G \\
\hline 5 & $\mathrm{~N}$ & - & $\mathrm{N}$ & - & $\mathrm{L}(73 \%)$ & - & $\mathrm{N}$ & - & $\mathrm{G}(38 \%)$ & $\mathrm{G}(34 \%)$ & - \\
\hline 6 & $\mathrm{~N}$ & - & $\mathrm{G}(29 \%)$ & - & $\mathrm{N}$ & - & $\mathrm{N}$ & - & $\mathrm{G}(29 \%)$ & $\mathrm{G}(30 \%)$ & - \\
\hline 7 & $\mathrm{~N}$ & - & $\mathrm{N}$ & - & - & - & $\mathrm{G}(27 \%)$ & - & $\mathrm{N}$ & $\mathrm{G}(40 \%)$ & - \\
\hline 8 & $\mathrm{G}(24 \%)$ & - & $\mathrm{N}$ & - & - & - & - & - & G (34\%) & - & - \\
\hline 9 & $\mathrm{G}(6 \%)$ & - & $\mathrm{N}$ & - & $\mathrm{N}$ & - & $\mathrm{N}$ & - & $\mathrm{N}$ & $\mathrm{N}(6 \%)$ & - \\
\hline 10 & - & - & - & - & - & - & - & - & G (43\%) & - & - \\
\hline 11 & $\mathrm{G}(50 \%)$ & G & N (NA) & $\mathrm{N}$ & N (NA) & $\mathrm{N}$ & G (32\%) & G & G (35\%) & G (18\%) & G \\
\hline 12 & $G(25 \%)$ & - & $\mathrm{N}$ & - & $\mathrm{L}(60 \%)$ & - & $\mathrm{G}(22 \%)$ & - & $\mathrm{N}$ & $\mathrm{G}(23 \%)$ & - \\
\hline 13 & $\mathrm{~N}$ & - & $\mathrm{L}(64 \%)$ & - & $\mathrm{N}$ & - & $\mathrm{N}$ & - & $\mathrm{G}(43 \%)$ & $\mathrm{G}(20 \%)$ & - \\
\hline 14 & $\mathrm{G}(23 \%)$ & G & G ( $42 \%)$ & $\mathrm{N}$ & $\mathrm{N}$ & $\mathrm{L}$ & G (42\%) & $\mathrm{N}$ & G (33\%) & $\mathrm{G}(32 \%)$ & G \\
\hline 15 & $\mathrm{~N}$ & $\mathrm{~N}$ & G $(22 \%)$ & $\mathrm{N}$ & $\mathrm{N}$ & $\mathrm{N}$ & $\mathrm{N}$ & G & G (50\%) & G (29\%) & G \\
\hline 16 & G (5\%) & - & - & - & - & - & $\mathrm{N}$ & - & $\mathrm{G}(18 \%)$ & $\mathrm{G}(27 \%)$ & - \\
\hline 17 & $\mathrm{G}(15 \%)$ & $\mathrm{N}$ & $\mathrm{G}(25 \%)$ & $\mathrm{N}$ & $\mathrm{L}(66 \%)$ & $\mathrm{N}$ & $\mathrm{N}$ & $\mathrm{N}$ & $\mathrm{N}$ & $N(10 \%)$ & $\mathrm{N}$ \\
\hline 18 & G (22\%) & - & - & - & $\mathrm{G}(16 \%)$ & - & - & - & $\mathrm{N}$ & $\mathrm{N}(10 \%)$ & - \\
\hline 19 & $G(39 \%)$ & G & $\mathrm{N}$ & $\mathrm{N}$ & - & $\mathrm{L}$ & - & G & $\mathrm{G}(33 \%)$ & $\mathrm{G}(18 \%)$ & G \\
\hline 20 & $\mathrm{G}(15 \%)$ & $\mathrm{N}$ & $\mathrm{N}$ & $\mathrm{N}$ & - & $\mathrm{L}$ & $\mathrm{N}$ & $\mathrm{N}$ & $G(19 \%)$ & $\mathrm{G}(30 \%)$ & $\mathrm{N}$ \\
\hline \multicolumn{12}{|c|}{ FISH cutoff value } \\
\hline Gain & $4 \%$ & & $19 \%$ & & $13 \%$ & & $20 \%$ & & $17 \%$ & $16 \%$ & \\
\hline Loss & $73 \%$ & & $62 \%$ & & $60 \%$ & & $70 \%$ & & & & \\
\hline
\end{tabular}

Abbreviations: G, copy number gain; L, copy number loss; N, normal.

target marker due to its interaction with HRAS and function in degrading cellular proteins as well as because its genomic implications for intestinal T-cell lymphomas (Carreras J and co-workers, unpublished observations). As a tumor suppressor, HACE1 inactivation in mice leads to the generation of cancer, a process that is enhanced with the addition of 'second hits' such as mutations in p53. HACE1 is frequently downregulated in human tumors. ${ }^{30,31}$ Methylation of HACE1 has been identified in gastric and colorectal cancers and its expression is markedly reduced in nasal type extranodal NK/T-cell lymphoma. ${ }^{32}$ Recently, the 6q21-22 region, which contains HACE1, has been confirmed as a celiac disease susceptibility locus (possibly mutated). ${ }^{33}$ In our series, loss could not be identified by array comparative genomic hybridization, and loss frequency was observed in only $6 \%(1 / 16)$ of cases by FISH. Therefore, the loss of $6 q$ is not characteristic of EATL cases in Japan and may be useful for exclusion of peripheral T-cell lymphoma, not otherwise specified and Extranodal NK/T lymphoma, nasal type.

We observed a gain of 8 q24 in $25 \%(2 / 8)$ of cases by array comparative genomic hybridization. This data is in agreement with previously reported data of EATL Type I (27\%). ${ }^{15}$ In addition, there have been no reports on the loss of $19 \mathrm{q} 33.33$ and gain of $4 \mathrm{p} 15$, $8 \mathrm{p} 11,12 \mathrm{p} 13$, and $16 \mathrm{q} 23$, which we have observed to be minimal common regions.
In conclusion, EATL cases in Japan have a phenotype of $\mathrm{CD}^{+} \mathrm{CD}^{+} 6^{+}$cytotoxic lymphocytes and increased number of intraepithelial lymphocytes, yet patients lack history of celiac disease. The results of this study point out a more blurred distinction between EATL Type I and II in Asian countries. Although it remains to be clarified what immunological background triggers EATL pathogenesis, the genomic profiles of EATL in Japan is characterized by multiple regions of copy number gains and losses, with the most characteristic being the 9q34 gain, irrespective of the cell origin of $\alpha \beta$-Tcells and $\gamma \delta$-T-cells.

\section{Acknowledgments}

We thank Dr Lluis Armengol from Quantitative Genomic Medicine Laboratories (Barcelona, Spain) for his work in the array comparative genomic hybridization technique. This study was supported in part by a grant-in-aid for Scientific Research (no. 25860278) from the Ministry of Education, Science, and Culture of Japan.

\section{Disclosure/conflict of interest}

The authors declare no conflict of interest. 


\section{References}

1 Isaacson PG, Chott A, Ott $\mathrm{G}$ et al. Enteropathyassociated T-cell lymphoma. In: Swerdlow SH, Campo E, Harris NL, Jaffe ES et al. (eds) WHO Classification of Tumors of Haematopoietic and Lymphoid Tissues4th ednInternational Agency for Research Cancer Press: Lyon, FranceLyon, France2008, pp 289-291.

2 Delabie J, Holte H, Vose JM et al. Enteropathyassociated T-cell lymphoma: clinical and histological findings from the international peripheral T-cell lymphoma project. Blood 2011;118:148-155.

3 Raderer M, Troch M, Kiesewetter B et al. Second line chemotherapy in patients with enteropathy-associated T cell lymphoma: a retrospective single center analysis. Ann Hematol 2012;91:57-61.

4 Ferreri AJ, Zinzani PL, Govi S, Pileri SA. Enteropathyassociated T-cell lymphoma. Crit Rev Oncol Hematol 2011;79:84-90.

5 Yasuoka H, Masuo T, Hashimoto K et al. Enteropathytype T-cell lymphoma that was pathologically diagnosed as celiac disease. Intern Med. 2007;46: 1219-1224.

6 Takeshita M, Nakamura S, Kikuma K et al. Pathological and immunohistological findings and genetic aberrations of intestinal enteropathy-associated T cell lymphoma in Japan. Histopathology 2011;58:395-407.

7 Tan SY, Chuang SS, Tang T et al. Type II EATL (epitheliotropic intestinal T-cell lymphoma): a neoplasm of intra-epithelial T-cells with predominant CD8 $\alpha \alpha$ phenotype. Leukemia 2013;27:1688-1696.

8 Chan JK, Chan AC, Cheuk W et al. Type II enteropathyassociated T-cell lymphoma: a distinct aggressive lymphoma with frequent $\gamma \delta \mathrm{T}$-cell receptor expression. Am J Surg Pathol 2011;35:1557-1569.

9 Tse E, Gill H, Loong F et al. Type II enteropathyassociated T-cell lymphoma: a multicenter analysis from the Asia Lymphoma Study Group. Am J Hematol 2012;87:663-668.

10 Kato A, Takiuchi Y, Aoki K et al. Enteropathyassociated T-cell lymphoma type II complicated by autoimmune hemolytic anemia. J Clin Exp Hematop 2011;51:119-123.

11 Ogata M, Ota Y, Nanno M et al. Activation of intraepithelial lymphocytes; their morphology, marker expression and ultimate fate. Cell Tissue Res 2014;356: 217-230.

12 Han SH, Joo M, Kim KM. High proportion of granzyme $\mathrm{B}+$ intraepithelial lymphocytes contributes to epithelial apoptosis in Helicobacter pylori-associated lymphocytic gastritis. Helicobacter 2013;18:290-298.

13 Ogata M, Ota Y, Matsutani $\mathrm{T}$ et al. Granzyme B-dependent and perforin-independent DNA fragmentation in intestinal epithelial cells induced by anti-CD3 mAb-activated intra-epithelial lymphocytes. Cell Tissue Res 2013;352:287-300.

14 Zettl A, Ott G, Makulik A et al. Chromosomal gains at 9q characterize enteropathy-type T-cell lymphoma. Am J Pathol 2002;161:1635-1645.

15 Deleeuw RJ, Zettl A, Klinker E et al. Whole-genome analysis and HLA genotyping of enteropathy-type T-cell lymphoma reveals 2 distinct lymphoma subtypes. Gastroenterology 2007;132:1902-1911.

16 Langerak AW, Groenen $\mathrm{PJ}$, Brüggemann $\mathrm{M}$ et al. EuroClonality/BIOMED-2 guidelines for interpretation and reporting of Ig/TCR clonality testing in suspected lymphoproliferations. Leukemia 2012;26:2159-2171.
17 Salaverria I, Royo C, Carvajal-Cuenca A et al. CCND2 rearrangements are the most frequent genetic events in cyclin D1(-) mantle cell lymphoma. Blood 2013;121: 1394-1402.

18 Leprêtre F, Villenet C, Quief S et al. Waved aCGH: to smooth or not to smooth. Nucleic Acids Res 2010; 38:e94.

19 Ye H, Liu H, Attygalle A et al. Variable frequencies of $\mathrm{t}$ $(11 ; 18)(q 21 ; q 21)$ in MALT lymphomas of different sites: significant association with CagA strains of $\mathrm{H}$ pylori in gastric MALT lymphoma. Blood 2003;102:1012-1018.

20 Ventura RA, Martin-Subero JI, Jones $\mathrm{M}$ et al. FISH analysis for the detection of lymphoma-associated chromosomal abnormalities in routine paraffinembedded tissue. J Mol Diagn 2006;8:141-151.

21 Chanudet E, Ye H, Ferry J et al. A20 deletion is associated with copy number gain at the TNFA/B/C locus and occurs preferentially in translocationnegative MALT lymphoma of the ocular adnexa and salivary glands. J Pathol 2009;217:420-430.

22 Garcia-Herrera A, Song JY, Chuang SS et al. Nonhepatosplenic $\gamma \delta$ T-cell lymphomas represent a spectrum of aggressive cytotoxic T-cell lymphomas with a mainly extranodal presentation. Am J Surg Pathol 2011;35:1214-1225.

23 Roullet M, Gheith SM, Mauger J et al. Percentage of $\gamma \delta$ $\mathrm{T}$ cells in panniculitis by paraffin immunohistochemical analysis. Am J Clin Pathol 2009;131:820-826.

24 Hara H, Saito T. CARD9 versus CARMA1 in innate and immunity. Trends Immunol 2009;30:234-242.

25 Nakamura S, Nakamura S, Matsumoto T et al. Overexpression of caspase recruitment domain (CARD) membrane-associated guanylate kinase 1 (CARMA1) and CARD9 in primary gastric B-cell lymphoma. Cancer 2005;104:1885-1893.

26 Zhou Y, Ye H, Martin-Subero JI et al. The pattern of genomic gains in salivary gland MALT lymphomas. Haematologica 2007;92:921-927.

27 Verkarre V, Romana SP, Cellier C et al. Recurrent partial trisomy 1q22-q44 in clonal intraepithelial lymphocytes in refractory celiac sprue. Gastroenterology 2003;125:40-46.

28 Akyurek N, Drakos E, Giaslakiotis K et al. Differential expression of CKS-1B in typical and blastoid variants of mantle cell lymphoma. Hum Pathol 2010;41: 1448-1455.

29 Björck E, Ek S, Landgren O et al. High expression of cyclin B1 predicts a favorable outcome in patients with follicular lymphoma. Blood 2005;105:2908-2915.

30 Anglesio MS, Evdokimova V, Melnyk N et al. Differential expression of a novel ankyrin containing E3 ubiquitin-protein ligase, Hace1, in sporadic Wilms' tumor versus normal kidney. Hum Mol Genet 2004;13: 2061-2074.

31 Zhang L, Anglesio MS, O'Sullivan M et al. The E3 ligase HACE1 is a critical chromosome 6q21 tumor suppressor involved in multiple cancers. Nat Med 2007;13:1060-1069.

32 Huang Y, de Reyniès A, de Leval L et al. Gene expression profiling identifies emerging oncogenic pathways operating in extranodal NK/T-cell lymphoma, nasal type. Blood 2010;115:1226-1237.

33 Einarsdottir E, Bevova MR, Zhernakova A et al. Multiple independent variants in 6q21-22 associated with susceptibility to celiac disease in the Dutch, Finnish and Hungarian populations. Eur J Hum Genet 2011;19: 682-686. 